\title{
Computational modelling of local calcium ions release from calcium phosphate-based scaffolds
}

\author{
Varun Manhas $^{1,2,3}$ - Yann Guyot ${ }^{1,3}$. Greet Kerckhofs ${ }^{3,4}$ - Yoke Chin Chai ${ }^{3,4}$. \\ Liesbet Geris ${ }^{1,2,3}$
}

Received: 26 April 2016 / Accepted: 29 August 2016

(C) Springer-Verlag Berlin Heidelberg 2016

\begin{abstract}
A variety of natural or synthetic calcium phosphate (CaP)-based scaffolds are currently produced for dental and orthopaedic applications. These scaffolds have been shown to stimulate bone formation due to their biocompatibility, osteoconductivity and osteoinductivity. The release of the $\mathrm{Ca}^{2+}$ ions from these scaffolds is of great interest in light of the aforementioned properties. It can depend on a number of biophysicochemical phenomena such as dissolution, diffusion and degradation, which in turn depend on specific scaffold characteristics such as composition and morphology. Achieving an optimal release profile can be challenging when relying on traditional experimental work alone. Mathematical modelling can complement experimentation. In this study, the in vitro dissolution behaviour of four CaP-based scaffold types was investigated experimentally. Subsequently, a mechanistic finite element method model based on biophysicochemical phenomena and specific
\end{abstract}

Electronic supplementary material The online version of this article (doi:10.1007/s10237-016-0827-9) contains supplementary material, which is available to authorized users.

$\triangle$ Liesbet Geris

liesbet.geris@ulg.ac.be

http://www.biomech.ulg.ac.be

1 Biomechanics Research Unit, GIGA In Silico Medicine, U. Liège, Chemin des Chevreuils 1, B52/3, 4000 Liège, Belgium

2 Biomechanics Section, Department of Mechanical Engineering, KU Leuven, Celestijnenlaan 300 C, Bus 2419, 3001 Heverlee, Belgium

3 Prometheus, Division of Skeletal Tissue Engineering Leuven, KU Leuven, O\&N 1, Herestraat 49, Bus 813, 3000 Leuven, Belgium

4 Tissue Engineering Unit, Skeletal Biology and Engineering Research Center, KU Leuven, O\&N 1, Herestraat 49, Bus 831, 3000 Leuven, Belgium scaffold characteristics was developed to predict the experimentally observed behaviour. Before the model could be used for local $\mathrm{Ca}^{2+}$ ions release predictions, certain parameters such as dissolution constant $\left(k_{\mathrm{dc}}\right)$ and degradation constant $\left(k_{\mathrm{sc}}\right)$ for each type of scaffold were determined by calibrating the model to the in vitro dissolution data. The resulting model showed to yield release characteristics in satisfactory agreement with those observed experimentally. This suggests that the mathematical model can be used to investigate the local $\mathrm{Ca}^{2+}$ ions release from CaP-based scaffolds.

Keywords Calcium phosphate (CaP)-based scaffold . Dissolution - Diffusion - Degradation - Mathematical model $\cdot$ Finite element method (FEM)

\section{Introduction}

Calcium phosphate $(\mathrm{CaP})$ materials are widely used for dental and orthopaedic applications in the regeneration of bone defects, because of their chemical similarity to native bone tissue and their ability to induce bone formation along with providing structural support (Lanao et al. 2011). The release of calcium $\left(\mathrm{Ca}^{2+}\right)$ and phosphate $\left(\mathrm{P}_{i}\right)$ ions by dissolution is believed to affect the bone cell chemotaxis, proliferation and differentiation. It has been reported in various in vitro studies that calcium ion concentrations between 2 and $8 \mathrm{mM}$ have a profound impact on bone cell fate but optimum in vivo calcium concentrations are still unknown (Bianchi et al. 2014; Bléry et al. 2014; Carlier et al. 2011; Chai 2012a, b, c; Charles-Harris et al. 2008; Danoux 2015; Hong et al. 2014; Karadzic et al. 2015; Lobo et al. 2015; Mazón et al. 2015; Roberts et al. 2011; Shih et al. 2014). Once the CaP materials are implanted in vivo, they should induce bone formation but should eventually completely degrade and be absorbed 
by the body. Ideally, the degradation rate should be similar to the rate of bone formation (Wu and Ding 2005).

There are three major types of $\mathrm{CaP}$ materials used for bone tissue engineering applications: hydroxyapatite (HA, $\left.\mathrm{Ca}_{10}\left(\mathrm{PO}_{4}\right)_{6}(\mathrm{OH})_{2}\right)$, beta-tricalcium phosphate $(\beta$-TCP, $\left.\mathrm{Ca}_{3}\left(\mathrm{PO}_{4}\right)_{2}\right)$ and biphasic calcium phosphate (BCP). HA can cause infections due to low degradation, whereas high degradation of $\beta$-TCP diminishes its structural function. Having a mixture of HA and $\beta$-TCP results in BCP, which is more degradable than HA whereas more stable than $\beta$-TCP. As a result, the bioreactivity of BCPs can be controlled by manipulating the HA/ $\beta$-TCP ratio (Hong et al. 2014). In addition to the chemical composition (HA/ $\beta$-TCP ratio), varying surface-structural properties, such as macro- and microporosity, specific surface area, roughness and overall geometry, also affect bone formation (Bohner and Baumgart 2004; Danoux 2015; Lobo et al. 2015; Mazón et al. 2015). Moreover, it has been reported that the porosity or the pore size can influence the degradation rate. Scaffolds with high porosity or small pore size degrade more slowly than those with low porosity or large pore size (Wu and Ding 2005). Given their widespread medical use, there remains a strong demand to design and develop CaP-based bone substitutes that have optimal chemical composition and surface-structural properties for the desired bone formation (Bohner and Baumgart 2004). However, experimentally determining the ideal combinations of chemical composition along with surface-structural properties to maximize in vivo bone formation for specific applications can be challenging. Nevertheless, testing these different combinations in silico can save research time and costs.

Accurate mathematical models can be used to facilitate the development of optimized degradable bone substitutes and other biomaterials by allowing rapid evaluation and validation of experimental parameters and also minimizing the number of required experimental studies (Frenning 2004; Kaunisto et al. 2013; Lao et al. 2011; Masaro and Zhu 1999; Siepmann et al. 1999; Siepmann and Siepmann 2013). In addition, they also allow quantitative understanding of the physical, chemical and biological phenomena involved in the controlled release of ions or molecules (Siepmann and Göpferich 2001; Snorradóttir et al. 2013). Due to significant advances in information technology, mathematical modelling of biomaterial behaviour is increasing its academic and industrial importance, which makes it an integral part of future research and development in bone tissue engineering. Concerning the development of optimized degradable scaffolds, the importance of such models lies in their relevance during the designing stage as well as the experimental verification of degradation and release mechanism. However, it is unlikely that there will be one mathematical model that will be able to describe any type of release of ions or molecules from biomaterials. It is much more likely that there will be different mathematical models, applicable to specific types of systems that differ in geometry and composition (Arifin et al. 2006; Brazel and Peppas 2000; Dash et al. 2010; Fredenberg et al. 2011; Frenning 2003; Frenning et al. 2005; Frenning and Strømme 2003; Frenning et al. 2003; Polakovič et al. 1999; Siepmann and Peppas 2011; Siepmann and Siepmann 2008). Over the past few years, a few lattice-based three-dimensional (3D) mathematical models have been proposed to study the in vivo bone formation process in porous biodegradable $\mathrm{CaP}$ scaffolds (Adachi et al. 2006; Byrne et al. 2007; Sun et al. 2013). Adachi et al. (2006) proposed a mathematical model of in vivo bone tissue regeneration that consisted of scaffold degradation due to hydrolysis. Byrne et al. (2007) proposed a mathematical model of in vivo tissue differentiation and bone regeneration in a degrading scaffold as a function of porosity, Young's modulus, and dissolution rate. Sun et al. (2013) proposed a multiscale model of a biodegradable porous calcium phosphate $(\mathrm{CaP})$ scaffold to examine the effects of pore size and porosity on bone formation and angiogenesis. However, the above-mentioned models being lattice-based did not capture the actual geometry of the CaP scaffolds. Additionally, the models had phenomenological description of the degradation process as they were not interested in the degradation products themselves but rather in the changing stiffness and porosity of the scaffold.

As the in vivo calcium release cannot be measured accurately, our first objective was to investigate the in vitro dissolution behaviour of CaP-based scaffolds and develop a computational model that can replace the dissolution tests in the future. Certainly, our next objective will be to implement the model to predict the in vivo bone formation process. To the best of our knowledge, we did not find any previous computational studies describing the in vitro dissolution and degradation of CaP-based scaffolds over time using accurate geometries. Therefore, in this paper we follow a combined experimental modelling approach to be able to accurately describe the in vitro dissolution and degradation of CaP-based scaffolds over time, as schematically described in Fig. 1. The in vitro dissolution behaviour of four CaP-based scaffold types (Bio-Oss ${ }^{\circledR}$, Integra-Mozaik ${ }^{\mathrm{TM}}$, $\mathrm{MBCP}^{\mathrm{TM}}$ and ReproBone ${ }^{\mathrm{TM}}$ ) was investigated in phosphatebuffered saline (PBS). For mathematical simulations, we developed a mechanistic finite element method (FEM) model based on the Noyes-Whitney equation, the Fick's second law of diffusion equation and the level-set method (LSM). The model was dependent on biophysicochemical phenomena such as dissolution, diffusion and degradation along with specific scaffold characteristics such as composition, size and shape. The microCT data provided input for the geometrical domain of the model. The values for model parameters such as the dissolution constant $\left(k_{\mathrm{dc}}\right)$ and the degradation constant $\left(k_{\mathrm{sc}}\right)$ were estimated from the $\mathrm{Ca}^{2+}$ ions release data 


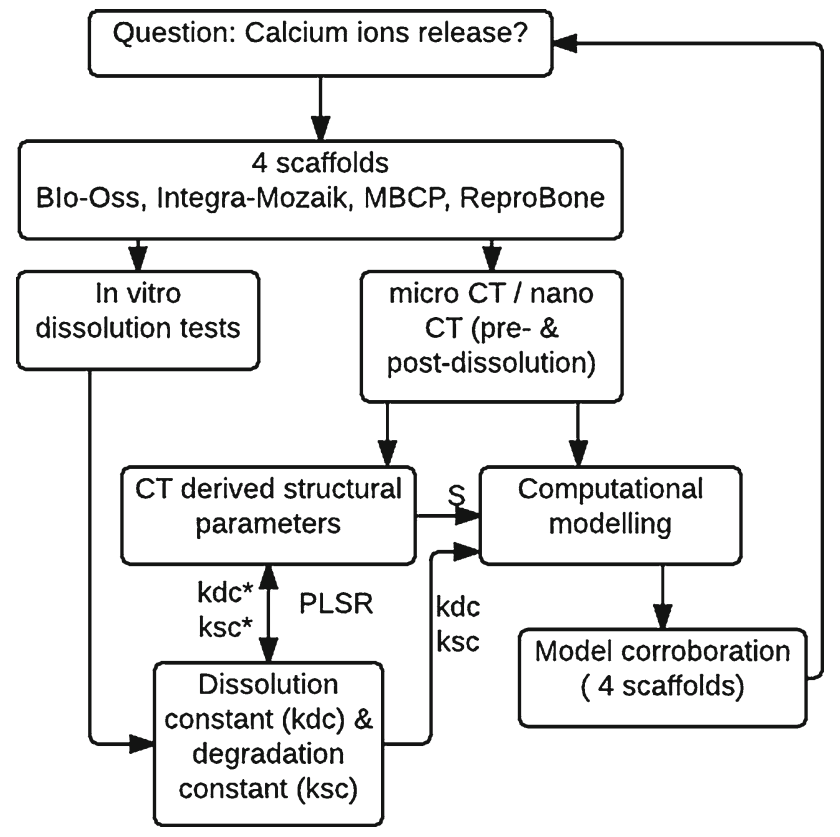

Fig. 1 Schematic diagram of combined experimental modelling approach showing the initial estimation of the dissolution constant $\left(k_{\mathrm{dc}}\right)$ and degradation constant $\left(k_{\mathrm{sc}}\right)$ from the in vitro dissolution tests and then deriving the $k_{\mathrm{dc}}^{*}$ and the $k_{\mathrm{sc}}^{*}$ by linking the $k_{\mathrm{dc}}$ and the $k_{\mathrm{sc}}$, respectively, to the structural properties measured in the microCT analysis using partial least squares regression (PLSR). $S$ denotes the $\mathrm{CaP}$ surface area in the scaffold

measured from dedicated dissolution experiments. Additionally, convergence and sensitivity analyses were carried out to investigate in more detail certain model parameters relevant to $\mathrm{Ca}^{2+}$ ions release. A partial least square regressions (PLSR) analysis was used to identify linear relationships between scaffold characteristics and the $k_{\mathrm{dc}}$ and $k_{\mathrm{sc}}$ values which were used to estimate $k_{\mathrm{dc}}^{*}$ and $k_{\mathrm{sc}}^{*}$ values. The model outputs for both the sets of parameters were then compared. Finally, the linear relationships derived using PLSR were used to investigate in silico the dissolution behaviour of $\mathrm{CaP}$ biomaterials composed of different combinations of HA and $\beta$-TCP.

\section{Materials and methods}

\subsection{Calcium phosphate scaffolds}

Four types of commercially available and clinically used $\mathrm{CaP}$ or $\mathrm{CaP} /$ collagen composite bone void fillers were used as scaffolds in this study (Table 1). Both Bio-Oss ${ }^{\circledR}$ (Geistlich, Wolhusen, Switzerland) and Integra-Mozaik ${ }^{\mathrm{TM}}$ (Integra LifeSciences, Plainsboro, USA) consist of CaP, which is distributed in an open collagen network, whereas $\mathrm{MBCP}^{\mathrm{TM}}$ (Biomatlante, Vigneux de Bretagne, France) and ReproBone $^{\mathrm{TM}}$ (Ceramisys Ltd., Sheffield, UK) only consist of $\mathrm{CaP}$. $\mathrm{CaP}$ of $\mathrm{Bio-Oss}{ }^{\circledR}$ consists of natural bone mineral made of bovine bone, whereas CaP of Integra-Mozaik ${ }^{\mathrm{TM}}$, $\mathrm{MBCP}^{\mathrm{TM}}$ and ReproBone ${ }^{\mathrm{TM}}$ is of synthetic origin. IntegraMozaik $^{\mathrm{TM}}$ is composed of $100 \% \beta$-tricalcium phosphate $\left(\beta\right.$-TCP), while $\mathrm{MBCP}^{\mathrm{TM}}$ and ReproBone ${ }^{\mathrm{TM}}$ are composed of $60 \%$ hydroxyapatite (HA) and $40 \% \beta$-TCP. All materials are described by the manufacturer as porous and in vivo resorbable. For this study, all the material blocks were cut with a scalpel in cubes with a volume of $27 \mathrm{~mm}^{3}$. All scaffolds were stored at room temperature and used under sterile conditions for all experiments.

\subsection{Structural characterization of the scaffolds using microfocus computed tomography}

The morphology and fractional composition (CaP/collagen/ pores) of the scaffolds were characterized prior to $(n=5)$ and after $(n=1)$ the dissolution tests using microCT on a Phoenix NanoTom S (GE Measurements and Control Solutions, Germany) at an isotropic voxel size of $3 \mu \mathrm{m}^{3}$ (Table 2). The samples were scanned using a source voltage of $60 \mathrm{kV}$ and current of $162 \mu \mathrm{A}$, and an aluminium filter of $0.3 \mathrm{~mm}$ was used to reduce beam hardening. The obtained 2400 radiographic images were reconstructed with Phoenix datos $\mid \mathrm{x}$ CT software, and the images were analysed using the inhouse developed software tool Morphing CiTy (ULg, Liege, Belgium) and the commercially available tool CTAn (Bruker micro-CT Kontich, Belgium). Thresholding of the greyscale histogram using a multilevel Otsu algorithm allowed the quantification of structural parameters for the complete scaffold and also for $\mathrm{CaP}$ and collagen separately (Sonnaert et al. 2015). The dry weight normalized to the initial total scaffold volume (TSV) of each scaffold was recorded prior to $(n=5)$ and after $(n=1)$ the dissolution test (Table 2).

\subsection{Calcium $\left(\mathrm{Ca}^{2+}\right)$ dissolution kinetics of the scaffolds}

The dissolution kinetics of the scaffolds $(n=3$, see Table 2$)$ in phosphate-buffered saline (PBS) solution (Biowhittaker ${ }^{\circledR}$, without $\mathrm{Ca}^{2+}$ and $\mathrm{Mg}^{2+}$ ions) at $37^{\circ} \mathrm{C}$ were investigated by placing scaffolds inside a $15-\mathrm{ml}$ Eppendorf tube placed on an orbital rotator rotating at $10 \mathrm{rpm}$. The PBS solution was refreshed at day 1, 3,6 and 21. All the samples were stored at $4{ }^{\circ} \mathrm{C}$. Before measurement, $240 \mu 1$ nitric acid was added to the samples to ensure there was no precipitation in the medium (Roberts et al. 2011). The released $\mathrm{Ca}^{2+}$ over 21 days was measured by a calcium micro ion electrode (Lazar Research Laboratories, Inc., USA).

\subsection{Statistics}

Data are expressed as mean \pm standard deviation (SD). Statistical significance was determined using the 1-way ANOVA with a post hoc Tukey test and the Student's $t$ test. Statistical 
Table 1 Four commercially available scaffolds used in this study with their structural and material characteristics as provided by the manufacturers. No detailed data were provided for Integra-Mozaik ${ }^{\mathrm{TM}}$ by the manufacturer

\begin{tabular}{llllll}
\hline Scaffold & CaP composition & Polymeric matrix type & Macropore size $(\mu \mathrm{m})$ & Micropore size $(\mu \mathrm{m})$ & Total porosity $(\%)$ \\
\hline Bio-Oss $^{\circledR}$ & Bovine bone granules & Col-I & $200-600$ & $0.1-1$ & 83 \\
Integra-Mozaik $^{\mathrm{TM}}$ & $100 \% \beta$-TCP & Col-I & - & - & - \\
MBCP $^{\mathrm{TM}}$ & $60 \%$ HA+40\% $\beta$-TCP & No polymeric matrix & $300-600$ & $<10$ & 70 \\
ReproBone $^{\mathrm{TM}}$ & $60 \%$ HA+40\% $\beta$-TCP & No polymeric matrix & $200-800$ & $1-10$ & 80 \\
\hline
\end{tabular}

Table 2 Overview of the experimental design used in this study

\begin{tabular}{|c|c|c|c|c|c|}
\hline & \multirow[t]{2}{*}{ Day } & \multicolumn{4}{|l|}{ (n) } \\
\hline & & Bio-Oss ${ }^{\circledR}$ & Integra-Mozaik $^{\mathrm{TM}}$ & $\mathrm{MBCP}^{\mathrm{TM}}$ & Repro Bone ${ }^{\mathrm{TM}}$ \\
\hline \multirow[t]{2}{*}{ microCT analysis } & D0 & 5 & 5 & 5 & 5 \\
\hline & D21 & 1 & 1 & 1 & 1 \\
\hline \multirow[t]{5}{*}{ Dissolution experiments } & D0 & 3 & 3 & 3 & 3 \\
\hline & D1 & 3 & 3 & 3 & 3 \\
\hline & D3 & 3 & 3 & 3 & 3 \\
\hline & D6 & 3 & 3 & 3 & 3 \\
\hline & D21 & 3 & 3 & 3 & 3 \\
\hline \multirow{2}{*}{$\begin{array}{l}\text { Normalized weight } \\
\text { measurements }\end{array}$} & D0 & 5 & 5 & 5 & 5 \\
\hline & D21 & 1 & 1 & 1 & 1 \\
\hline
\end{tabular}

The microCT data available for 1 scaffold at day 21 time point (after the dissolution test) was only used as a qualitative compliment to the study significance is indicated on all graphs as follows: $*: p<0.05$, $* *: p<0.01$, ***: $p<0.001$. Partial least square regression (PLSR) analysis was performed in JMP ${ }^{\circledR} 11$ (SAS Institute Inc., Cary, NC).

\section{Mathematical model}

\subsection{Model formulation}

In this paper, we developed a mathematical model to predict the in vitro dissolution behaviour of CaP-based scaffolds in PBS solution using the experimental dissolution results from Bio-Oss ${ }^{\circledR}$, Integra-Mozaik ${ }^{\mathrm{TM}}, \mathrm{MBCP}^{\mathrm{TM}}$ and ReproBone $^{\mathrm{TM}}$. As the initial solid calcium concentration was larger than the solubility of the $\mathrm{Ca}^{2+}$ ions in PBS solution, the solid and the dissolved $\mathrm{Ca}^{2+}$ coexisted at the same time during the dissolution process. The concentration change of dissolved $\mathrm{Ca}^{2+}$ ions with time was described using a diffusion-dissolution equation (1). The $\mathrm{Ca}^{2+}$ ions diffusion process was implemented using Fick's second law of diffusion, whereas the dissolution process was implemented based on the Noyes-Whitney equation (Frenning et al. 2005) where the rate of dissolution of a substance is described as a function of, amongst others, the concentration of the substance and its diffusion coefficient.

$$
\frac{\partial C}{\partial t}=\nabla \cdot(D \nabla C)+k_{\mathrm{dc}} \frac{S D}{V_{\mathrm{PBS}}}\left(C_{\mathrm{sol}}-C\right)
$$

where $C$ is the dissolved $\mathrm{Ca}^{2+}$ ions concentration $(\mathrm{mM})$, $D$ is the diffusion coefficient $\left(\mathrm{m}^{2} / \mathrm{s}\right), k_{\mathrm{dc}}$ is the dissolution constant $\left(\mathrm{m}^{-1}\right), S$ is the CaP surface area $\left(\mathrm{m}^{2}\right)$ calculated from the input microCT image (Table 3 ), $V_{\mathrm{PBS}}$ is the PBS volume $\left(1.5 \times 10^{-5} \mathrm{~m}^{3}\right)$ and $C_{\mathrm{sol}}$ is the solubility of the $\mathrm{Ca}^{2+}$ ions in PBS (mM). As the thickness of the boundary layer could not be measured experimentally, it was considered as a mathematical parameter that was incorporated in the $k_{\mathrm{dc}}$ in Eq. (1). The diffusion coefficient of $\mathrm{Ca}^{2+}$ ions in PBS solution at $37^{\circ} \mathrm{C}$ was considered to be constant and it was calculated using Stokes-Einstein equation (2) (Young et al. 1980) given below:

$D=\frac{k_{\mathrm{B}} T}{6 \pi \eta r}=2.83 \times 10^{-9} \mathrm{~m}^{2} / \mathrm{s}$

where $k_{\mathrm{B}}$ is the Boltzmann's constant $\left(1.38 \times 10^{-23} \mathrm{~m}^{2} \mathrm{~kg}\right.$ $\left.\mathrm{s}^{-2} \mathrm{~K}^{-1}\right), T$ is the absolute temperature $\left(37^{\circ} \mathrm{C}=310.5 \mathrm{~K}\right)$, $\eta$ is the viscosity of PBS at $37^{\circ} \mathrm{C}(0.0007 \mathrm{~Pa} \mathrm{~s})$ (Horbett et al. 1988) and $r$ is the radius of $\mathrm{Ca}^{2+}$ ion (114 pm) (Shannon 1976). The diffusion coefficient $(D)$ for calcium chloride $\left(\mathrm{CaCl}_{2}\right)$ in aqueous solutions at $310.15 \mathrm{~K}$ has been reported to be $(1.601 \pm 0.02) \times 10^{-9} \mathrm{~m}^{2} / \mathrm{s}$ (Ribeiro et al. 2008) which is of the same order of magnitude that was calculated theoretically in this study.

To implement degradation of the scaffold, we used the level-set method (LSM) to track implicitly the movement of the scaffold interface $\Gamma$ with velocity $v$ during the dissolution 


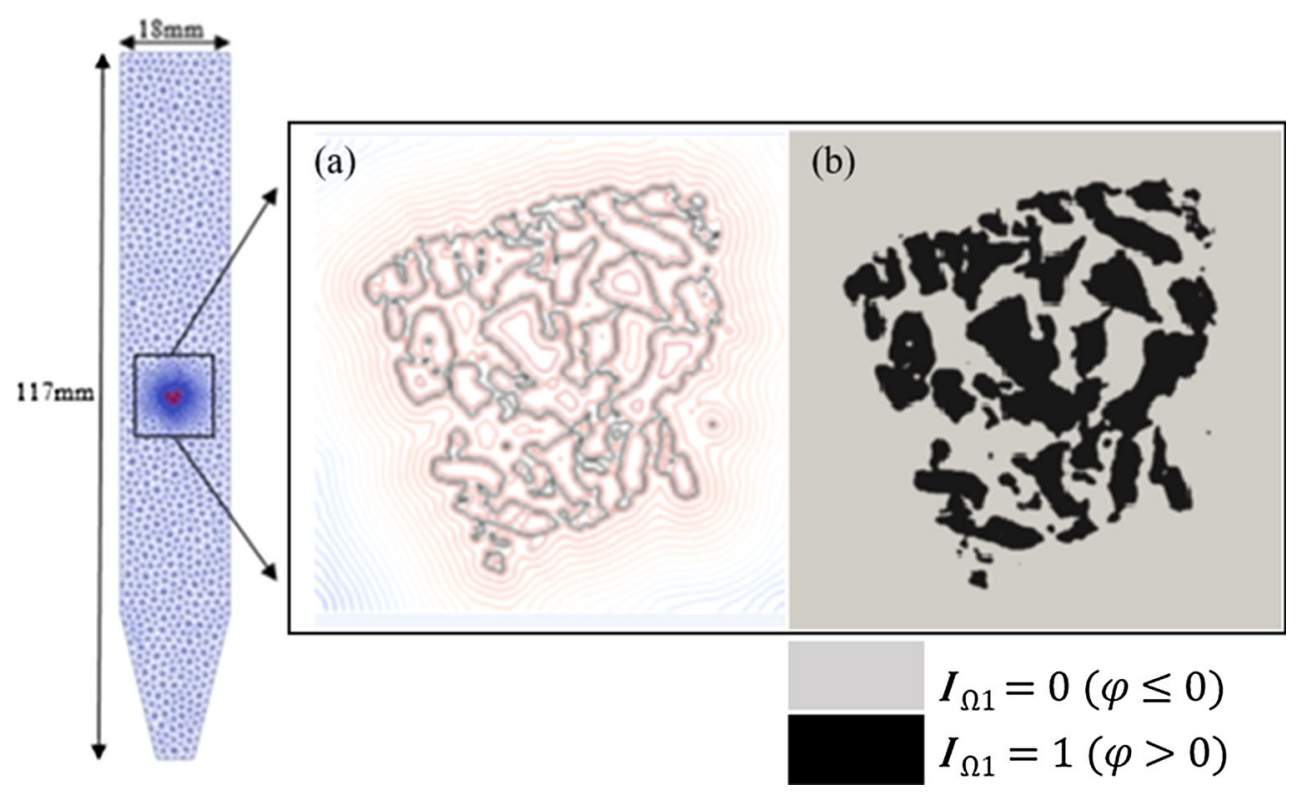

Fig. 2 Computational domain. Left Eppendorf tube filled with PBS and the scaffold. $a$ Iso-levels of $\varphi$ function (thick line represents the CaP interface $\Gamma$ where $\varphi=0) . b$ CaP indicator function $\left(\boldsymbol{I}_{\Omega 1}\right)$ computed over the domain

process. To implement the LSM, a microCT cross-sectional image of a scaffold was projected on a $2 \mathrm{D}$ finite element domain $\Omega \subset \mathbb{R}^{2}$. The domain was then decomposed into two sub-domains $\Omega 1$ and $\Omega 2$, and the interface/boundary between two partitions was denoted by $\Gamma$. The level-set function $(\varphi)$, a continuous scalar distance function, was then computed over the domain; $\varphi$ was positive in $\Omega 1$ (scaffold), negative in $\Omega 2$ (PBS solution) and zero on $\Gamma$ (boundary of the scaffold) (Fig. 2). The motion of the interface $(\Gamma)$ in the normal direction was described by the level-set equation (3) with a velocity field $v$ (Guyot et al. 2014):

$$
\frac{\partial \varphi}{\partial t}=v|\nabla \varphi|
$$

The degradation velocity $v$ was derived by dividing the dissolution term in Eq. (1) by $S \cdot C_{\mathrm{sol}} / V_{\mathrm{PBS}}$, where $S$ is the CaP surface area $\left(\mathrm{m}^{2}\right), C_{\text {sol }}$ is the solubility of $\mathrm{Ca}^{2+}$ ions in PBS (mM) and $V_{\mathrm{PBS}}$ is the PBS volume $\left(\mathrm{m}^{3}\right)$, thus resulting in degradation velocity as shown below in Eq. (4), with $k_{s c}$ being a dimensionless degradation constant.

$v=k_{\mathrm{sc}} k_{\mathrm{dc}} D\left(C_{\mathrm{sol}}-C\right) / C_{\mathrm{sol}}$

In this model, the solubility $\left(C_{\mathrm{sol}}\right)$ of $\mathrm{Ca}^{2+}$ ions was estimated to be $0.17 \mathrm{mM}$. The modelling of precipitation was not considered in this model as we did not detect precipitate formation during the experiments. The model also did not consider explicitly the influence of the $\mathrm{CaP}$ crystallinity or crystal size on the dissolution behaviour. The influence of collagen distribution around $\mathrm{CaP}$ in Bio-Oss ${ }^{\circledR}$ and IntegraMozaik ${ }^{\mathrm{TM}}$ on the $\mathrm{Ca}^{2+}$ ion dissolution was not modelled.

\subsection{Model implementation}

The mathematical domain for dissolution test simulation was represented by the front view of a 15-ml Eppendorf tube (Fig. 2). The model was implemented using the finite element method (FEM) with an open-source partial differential equation (PDE) solver FreeFem++ (http://freefem.org) (Hecht 2012). This solver is well adapted for the type of model developed in this study due to its ability to deal with complex geometries and meshes and its simplified way to treat any type of PDE by implementing its variational form.

To implement the Dirichlet-type boundary condition for $\mathrm{Ca}^{2+}$ ions on a penalized FEM domain, we used an indicator function $\left(\boldsymbol{I}_{\Omega 1}\right)$ which is described by Eq. (5), where $\varphi$ is the level-set function.

$I_{\Omega 1}:= \begin{cases}1 & \text { if } \boldsymbol{x} \in \Omega 1(\varphi>0) \\ 0 & \text { if } \boldsymbol{x} \notin \Omega 1(\varphi \leq 0)\end{cases}$

The initial condition for dissolved $\mathrm{Ca}^{2+}$ ions was set as:

$\mathrm{C}(0, \Omega)=0$ for dissolved $\mathrm{Ca}^{2+}$ ions

To impose no-flux boundary condition, we implemented the homogenous Neumann boundary condition on $\partial \Omega$ as shown below:

$\frac{\partial C}{\partial n}=0$

Essentially, a convergence study (Online resource 1) was executed to determine a time step as well as a mesh-size- 
independent numerical solution. This resulted in a time step of $3600 \mathrm{~s}$ and a number of elements being 115,460.

\subsection{Parameter estimation}

The model parameters used in this study were in part determined from physical laws, others were determined from the microCT data and yet some were estimated from the dissolution data. The diffusion coefficient $(D)$ of $\mathrm{Ca}^{2+}$ ions in PBS solution at $37{ }^{\circ} \mathrm{C}$ was calculated using the StokesEinstein equation (Young et al. 1980). The surface area $(S)$ of only $\mathrm{CaP}$ was calculated from the microCT image. The PBS volume $\left(V_{\mathrm{PBS}}\right)$ was determined from the dissolution experiments, whereas the solubility $\left(C_{\mathrm{sol}}\right)$ of the $\mathrm{Ca}^{2+}$ ions in PBS was estimated. For the dissolution constant $\left(k_{\mathrm{dc}}\right)$, first the order of magnitude was theoretically calculated using Eq. (1) with only the dissolution term. The experimentally measured value of $\mathrm{Ca}^{2+}$ ion dissolution for each scaffold at day 1 was used to determine theoretically the order of magnitude of $k_{\mathrm{dc}}$. The model was then calibrated with the experimental release data of $\mathrm{Ca}^{2+}$ ions for each scaffold at day 1 to obtain the best fit. The $k_{\mathrm{dc}}$ was estimated to be higher for Bio-Oss ${ }^{\circledR}$ and Integra-Mozaik $^{\mathrm{TM}}$. It was the highest for Bio-Oss ${ }^{\circledR}$ which was 2.7, 60.6 and 18.7 times higher than Integra-Mozaik ${ }^{\mathrm{TM}}$, $\mathrm{MBCP}^{\mathrm{TM}}$ and ReproBone ${ }^{\mathrm{TM}}$, respectively, (Table 3). The effect of the boundary layer was considered as a mathematical parameter that was incorporated in the parameter $k_{\mathrm{dc}}$. The degradation constant $\left(k_{\mathrm{sc}}\right)$ was estimated from the $\mathrm{CaP}$ volume and weight data from before and after the dissolution experiments (Online resource 2). It was estimated to be different between the fast degrading $\mathrm{CaP}$ types (Bio-Oss $\AA$ ) and Integra-Mozaik ${ }^{\mathrm{TM}}$ ) and the slow degrading $\mathrm{CaP}$ type $\left(\mathrm{MBCP}^{\mathrm{TM}}\right.$ and ReproBone ${ }^{\mathrm{TM}}$ ) (Table 3). Finally, the values for the sum of the squared residuals indicating the fit between the measured and the predicted $\mathrm{Ca}^{2+}$ ions release for each scaffold type are shown in Table 3.

\subsection{Model outlook}

With the aim of developing an accurate and credible model that allows predicting in vitro dissolution behaviour for $\mathrm{CaP}$ scaffolds outside of the training set without the need for additional experiments, a relationship was sought between the $k_{\mathrm{dc}}$ and $k_{\mathrm{sc}}$ values derived in this study and the structural and compositional characteristics of the scaffold materials. PLSR analysis allowed us to identify linear relationships between scaffold characteristics and the $k_{\mathrm{dc}}$ and $k_{\mathrm{sc}}$ values. To evaluate these relationships, they were used to estimate $k_{\mathrm{dc}}^{*}$ and $k_{\mathrm{sc}}^{*}$ values for all the scaffolds in the training set (Table 3) and the model outputs for both sets of parameters were then compared. The derived linear relationships were also used to estimate the $k_{\mathrm{dc}}^{*}$ and $k_{\mathrm{sc}}^{*}$ values for new CaP biomaterials with geometry as that of MBCP but with different combinations

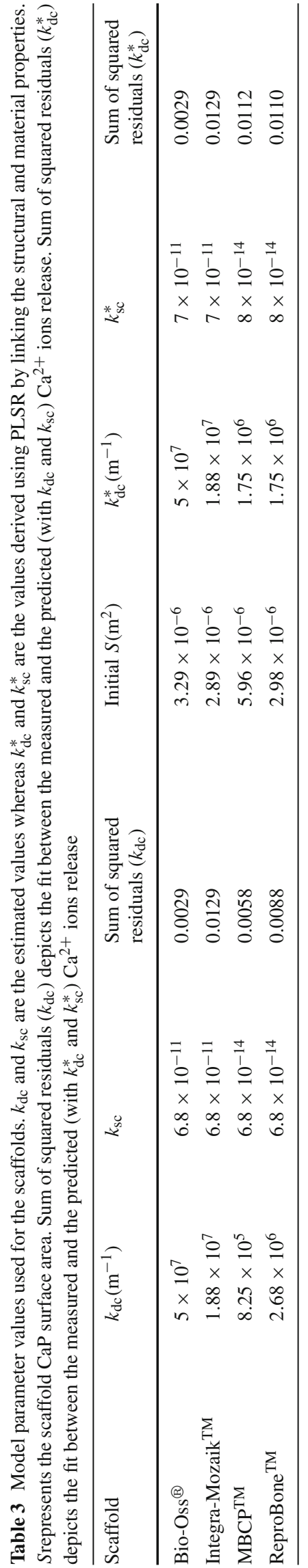


Table 4 PLSR-derived model parameter values $\left(k_{\mathrm{dc}}^{*}\right.$ and $\left.k_{\mathrm{sc}}^{*}\right)$ for combination of different material composition of $\mathrm{HA}$ and $\beta$-TCP

\begin{tabular}{lllll}
\hline CaP biomaterial & CaP composition & $k_{\mathrm{dc}}^{*}\left(\mathrm{~m}^{-1}\right)$ & $k_{\mathrm{sc}}^{*}$ & Initial $S\left(\mathrm{~m}^{2}\right)$ \\
\hline MBCP & $60 \% \mathrm{HA}+40 \% \beta$-TCP & $1.75 \times 10^{6}$ & $8 \times 10^{-14}$ & $5.96 \times 10^{-6}$ \\
B1 & $50 \% \mathrm{HA}+50 \% \beta$-TCP & $4.58 \times 10^{6}$ & $1 \times 10^{-11}$ & $5.96 \times 10^{-6}$ \\
B2 & $40 \% \mathrm{HA}+60 \% \beta$-TCP & $7.42 \times 10^{6}$ & $2 \times 10^{-11}$ & $5.96 \times 10^{-6}$ \\
B3 & $20 \% \mathrm{HA}+80 \% \beta$-TCP & $1.31 \times 10^{7}$ & $5 \times 10^{-11}$ & $5.96 \times 10^{-6}$ \\
B4 & $100 \% \beta$-TCP & $1.88 \times 10^{7}$ & $7 \times 10^{-11}$ & $5.96 \times 10^{-6}$ \\
\hline
\end{tabular}

B1-B4 represent different biomaterials of BCP type. $S$ represents the scaffold CaP surface area of HA and $\beta$-TCP (Table 4), which were then used to predict in silico the resulting dissolution behaviour. This allowed us to study in silico optimal biomaterial characteristics in order to obtain specific Ca release profiles.

\section{Results}

\subsection{Structural characteristics of the scaffolds}

To qualitatively and quantitatively investigate the structural characteristics of the scaffolds ( $n=5$, see Table 2$)$, microCT imaging was used. The reconstructed greyscale two-dimensional (2D) images (Fig. 3) show that Bio-Oss ${ }^{\circledR}$, $\mathrm{MBCP}^{\mathrm{TM}}$ and ReproBone ${ }^{\mathrm{TM}}$ were more homogenous in morphology throughout the scaffold than Integra-Mozaik ${ }^{\mathrm{TM}}$. We also observed that Integra-Mozaik ${ }^{\mathrm{TM}}$ had a distribution of collagen and $\mathrm{CaP}$ that was not consistent for the complete set of sections as it had collagen or $\mathrm{CaP}$ rich and poor zones, whereas the collagen in Bio-Oss ${ }^{\circledR}$ was more evenly distributed around $\mathrm{CaP}$ which was more homogenously distributed in the complete scaffold space. Both $\mathrm{MBCP}^{\mathrm{TM}}$ and ReproBone ${ }^{\mathrm{TM}}$ had a similar CaP matrix structure, with ReproBone ${ }^{\mathrm{TM}}$ having more circular-shaped pores and $\mathrm{MBCP}^{\mathrm{TM}}$ having on average a thicker $\mathrm{CaP}$ skeleton. The surface of Bio-Oss ${ }^{\circledR}$ was irregular, with collagen and $\mathrm{CaP}$ fully mixed together (Fig. 3).

The material characteristics of the scaffolds that were investigated before and after the dissolution tests using microCT were the $\mathrm{CaP}$ volume, collagen volume, total scaffold volume (TSV), total material volume (TMV), CaPspecific surface area $(\mathrm{SSA}=\mathrm{CaP}$ surface area/ $\mathrm{CaP}$ volume) and $\mathrm{CaP}$ thickness. The TMV for collagen containing scaffolds (Bio-Oss ${ }^{\circledR}$ and Integra-Mozaik ${ }^{\mathrm{TM}}$ ) is the sum of $\mathrm{CaP}$ volume and collagen volume, whereas the TMV for the pure $\mathrm{CaP}$ scaffolds ( $\mathrm{MBCP}^{\mathrm{TM}}$ and ReproBone ${ }^{\mathrm{TM}}$ ) is equal to the $\mathrm{CaP}$ volume. Due to inconsistent cutting, the TSV of the scaffolds showed variability, which is why all data were normalized to the initial TSV (leading to volume fractions, see Online Resource 2). There were significant differences in the initial CaP volume fractions [Online Resource 2(a)] and the initial TMV fractions [Online Resource 2(b)] between Bio-Oss ${ }^{\circledR}$, Integra-Mozaik ${ }^{\mathrm{TM}}, \mathrm{MBCP}^{\mathrm{TM}}$ and ReproBone ${ }^{\mathrm{TM}}$ $(p<0.01)$. There was also a significant difference $(p<$ 0.001 ) in the initial collagen volume fraction between BioOss ${ }^{\circledR}$ and Integra-Mozaik ${ }^{\mathrm{TM}}$. The initial collagen volume fraction was higher for Integra-Mozaik ${ }^{\mathrm{TM}}$ [Online Resource 2(c)]. There were also significant differences in the initial weight fractions between Bio-Oss ${ }^{\circledR}$, Integra-Mozaik ${ }^{\mathrm{TM}}$, $\mathrm{MBCP}^{\mathrm{TM}}$ and ReproBone ${ }^{\mathrm{TM}}(p<0.01)$ [Online Resource 2(d)].

\subsection{Experimental dissolution behaviour of the scaffolds}

To measure released $\mathrm{Ca}^{2+}$ ions from each biomaterial, scaffolds $(n=3)$ were incubated in PBS over a period of 21 days. The medium was changed periodically at various time points (day 1, 3, 6 and 21). In Fig. 4, the plots show the cumulative $\mathrm{Ca}^{2+}$ ion release measured over period of time. The scatter plots show the experimentally measured values, the solid lines show the $\mathrm{Ca}^{2+}$ ion release predicted by initially estimated $k_{\mathrm{dc}}$ and $k_{\mathrm{sc}}$ values and the dashed lines show the $\mathrm{Ca}^{2+}$ ion release predicted by PLSR-derived $k_{\mathrm{dc}}^{*}$ and $k_{\mathrm{sc}}^{*}$ values. The values shown for scatter plots are the averages of three repeated measurements from three different scaffolds, while the error bars indicate \pm SD.

In the experiments, the $\mathrm{Ca}^{2+}$ release was measured to be higher for Bio-Oss ${ }^{\circledR}$ and Integra-Mozaik ${ }^{\mathrm{TM}}$ in comparison with ReproBone ${ }^{\mathrm{TM}}$ and $\mathrm{MBCP}{ }^{\mathrm{TM}}$. Bio-Oss ${ }^{\circledR}$ had the highest overall $\mathrm{Ca}^{2+}$ release (Fig. 4a), whereas $\mathrm{MBCP}^{\mathrm{TM}}$ and ReproBone ${ }^{\mathrm{TM}}$ had the lowest and very similar release profiles (Fig. 4c, d).

The overall cumulative $\mathrm{Ca}^{2+}$ release for Bio-Oss ${ }^{\circledR}$ was measured to be approximately $1.45,1.68$ and 1.77 times higher than Integra-Mozaik ${ }^{\mathrm{TM}}, \mathrm{MBCP}^{\mathrm{TM}}$ and ReproBone ${ }^{\mathrm{TM}}$, respectively (Fig. 4). No significant differences in day 21 release were observed when comparing $\mathrm{MBCP}^{\mathrm{TM}}$ with Integra-Mozaik $^{\mathrm{TM}}$ and ReproBone ${ }^{\mathrm{TM}}(p>0.05)$.

\subsection{Mathematical dissolution behaviour of the scaffolds}

Once the model parameters such as $k_{\mathrm{dc}}$ and $k_{\mathrm{sc}}$ were estimated by calibrating the model to the experimental results, the model was allowed to run up to 21 days to predict the experimental dissolution behaviour. The solid lines in Fig. 4 depict 

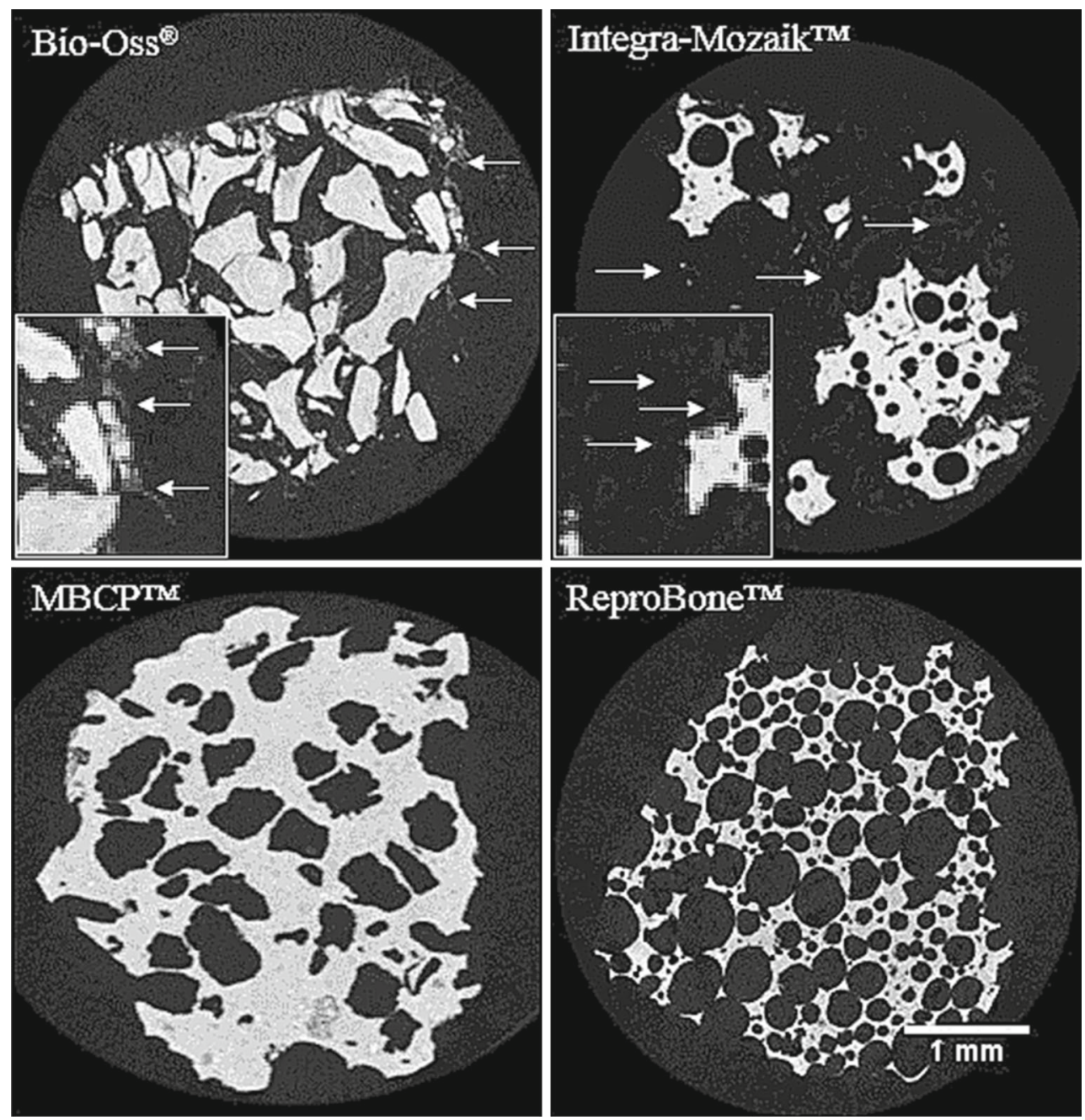

Fig. 3 Typical cross-sectional microCT images of the scaffolds. The CaP phase is clearly visible in light grey tones. Arrows indicate the collagen (dark grey) present in Bio-Oss ${ }^{\circledR}$ and Integra-Mozaik ${ }^{\mathrm{TM}}$. Scale bar $1 \mathrm{~mm}$

the predicted amount of $\mathrm{Ca}^{2+}$ ions released over the experimental measurement time. The values for the sum of the squared residuals indicating the fit between the measured and the predicted $\mathrm{Ca}^{2+}$ ions release (using $k_{\mathrm{dc}}$ and $k_{\mathrm{sc}}$ ) for each scaffold type are shown in Table 3. It is evident that there is an agreement between the predicted (solid lines) and the experimentally measured (scatter plots) cumulative release (Fig. 4). The model was also able to predict the spatio-temporal degradation and the dissolution of scaffolds over time. Figure $5 \mathrm{a}-\mathrm{c}$ depicts the degradation of Bio-Oss ${ }^{\circledR}$ predicted on day 0 , day 10 and day 21, whereas Fig. 5d-f depicts the local concentration of $\mathrm{Ca}^{2+}$ ions predicted during dissolution at the same time points.

Afterwards, the estimated $k_{\mathrm{dc}}$ and $k_{s c}$ were linked to the structural and material properties obtained from the microCT analysis, using PLSR (Table 3). From Eqs. (1), (8) and (9), it can be inferred that the dissolution and degradation of $\mathrm{CaP}$ in scaffolds are primarily governed by scaffold composition ( $\%$ bovine bone granules, $\% \beta$-TCP, $\% \mathrm{HA}$ ). Structural parameters such as the $\mathrm{CaP}$ surface area and porosity are taken into account through the input microCT image.

$k_{\mathrm{dc}} *=10^{5}(-95.83+5.95 * \%$ Bovine bone

$$
+2.83 * \% \beta-\mathrm{TCP})
$$

$k_{\mathrm{sc}} * 10^{-11}(6.8-0.1132 * \% \mathrm{HA})$

With the initially estimated $k_{\mathrm{dc}}$ and $k_{\mathrm{sc}}$ values, the model predicted $\mathrm{CaP}$ degradation between 9 and $18 \%$ for BioOss ${ }^{\circledR}$ and Integra-Mozaik ${ }^{\mathrm{TM}}$ whereas the predicted $\mathrm{CaP}$ degradation was between 0.5 and $5 \%$ for $\mathrm{MBCP}^{\mathrm{TM}}$ and ReproBone $^{\mathrm{TM}}$ (Fig. 6a). The microCT CaP volume change data normalized to the initial total scaffold volume (TSV) qualitatively confirmed the degradation prediction by the model (Fig. 6b). 

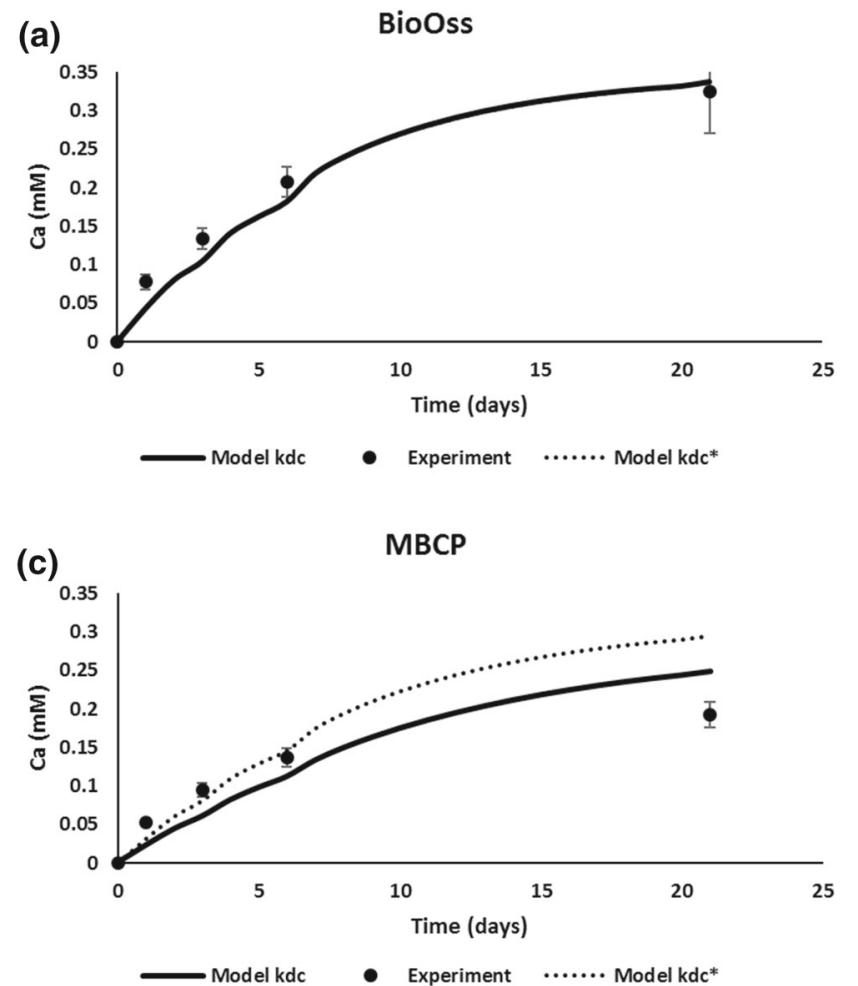

Fig. 4 Dissolution behaviour of different scaffolds observed experimentally (scatter plot), predicted mathematically [solid lines $\left(k_{\mathrm{dc}}\right)$ ] and model corroboration [dashed lines $\left.\left(k_{\mathrm{dc}}^{*}\right)\right]$. a Bio-Oss ${ }^{\circledR}$. b Integra-

\subsection{Model sensitivity analysis and outlook}

We carried out the single-parameter sensitivity analysis to investigate the effect of a number of estimated parameters on the simulation outcome, which is shown in Fig. 7. We investigated the effect of altering the value for solubility $\left(C_{\text {sol }}\right)$ and observed that it altered the final outcome. A $10 \%$ change in this value resulted in a corresponding $10 \%$ change in the predicted calcium release (Fig. 7a). Additionally, we investigated the influence of using other representative $2 \mathrm{D}$ images of Bio-Oss ${ }^{\circledR}$ and Integra-Mozaik ${ }^{\mathrm{TM}}$ in the model domain. We observed no significant differences in simulation results when using other images from the same stack for the Bio-Oss ${ }^{\circledR}$ scaffold (Fig. 7b); however, we did find larger differences for Integra-Mozaik ${ }^{\mathrm{TM}}$ which has a more heterogeneous structure (Fig. 7c).

Additionally, the obtained relationships between the $k_{\mathrm{dc}}$ and $k_{\mathrm{sc}}$ and the compositional characteristics were tested by using the $k_{\mathrm{dc}}^{*}$ and the $k_{\mathrm{sc}}^{*}$ values calculated from Eqs. (8) and (9) for each scaffold type to predict the experimental dis-
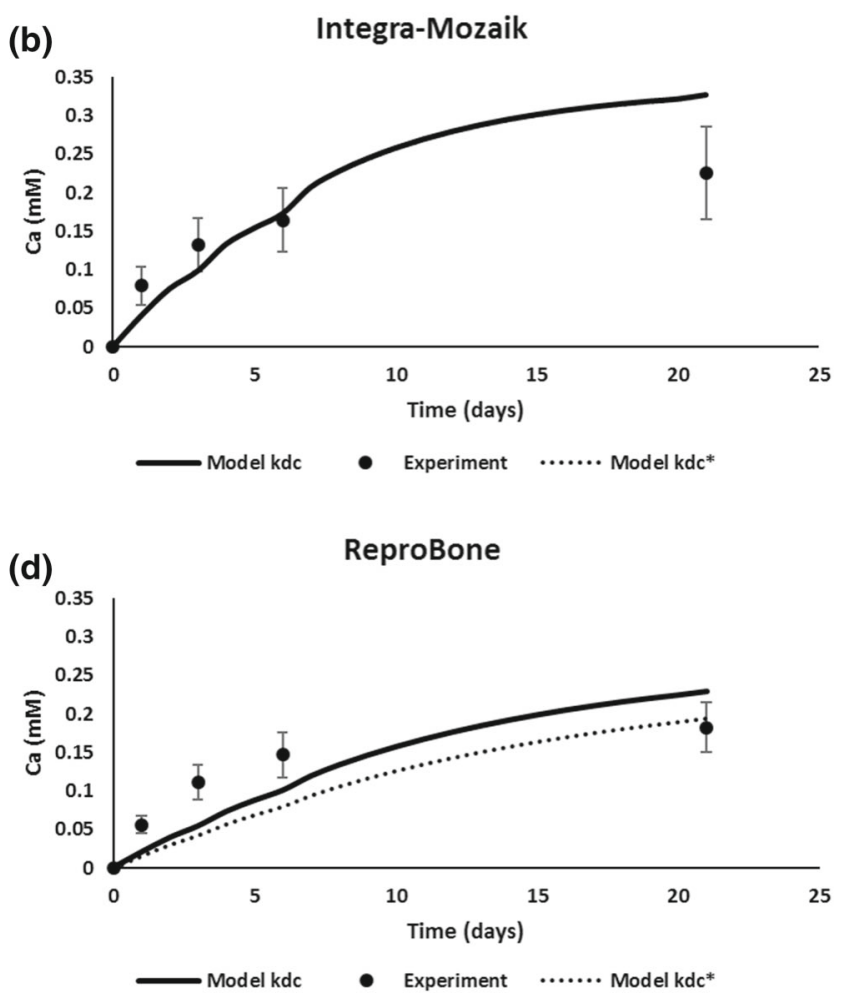

Mozaik $^{\mathrm{TM}}$. $\mathbf{c} \mathrm{MBCP}^{\mathrm{TM}}$. $\mathbf{d}$ ReproBone $\mathrm{TM}^{\mathrm{TM}}$. In a and $\mathbf{b}$ the dotted line coincides with the solid lines. Error bars indicate $\pm \mathrm{SD}(n=3)$

solution behaviour. Figure 4 shows a satisfactory agreement between the predicted (solid lines), PLSR derived (dashed lines) and experimentally measured (scatter plots) release of $\mathrm{Ca}^{2+}$ ions, which demonstrates acceptable accuracy of the model's representation of the real in vitro dissolution experimental set-up. The values for the sum of the squared residuals indicating the fit between the measured and the predicted $\mathrm{Ca}^{2+}$ ions release (using $k_{\mathrm{dc}}^{*}$ and $k_{\mathrm{sc}}^{*}$ ) for each scaffold type are shown in Table 3. In addition, for scaffold degradation, the PLSR-derived $k_{\mathrm{dc}}^{*}$ and $k_{\mathrm{sc}}^{*}$ values were similar to the initially estimated values, as was the model outcome obtained with those PLSR-derived values (Fig. 6). Finally, using the PLSR-derived linear relationships, the model was used to investigate the dissolution behaviour of a biomaterial with geometry as that of MBCP but with different combinations of HA and $\beta$-TCP (Fig. 8). It is clearly evident that the increase of $\beta$-TCP in biomaterial composition resulted in higher dissolution (Fig. 8a) along with higher degradation (Fig. 8b) whereas the effect of HA in biomaterial composition was completely opposite to $\beta$-TCP. 

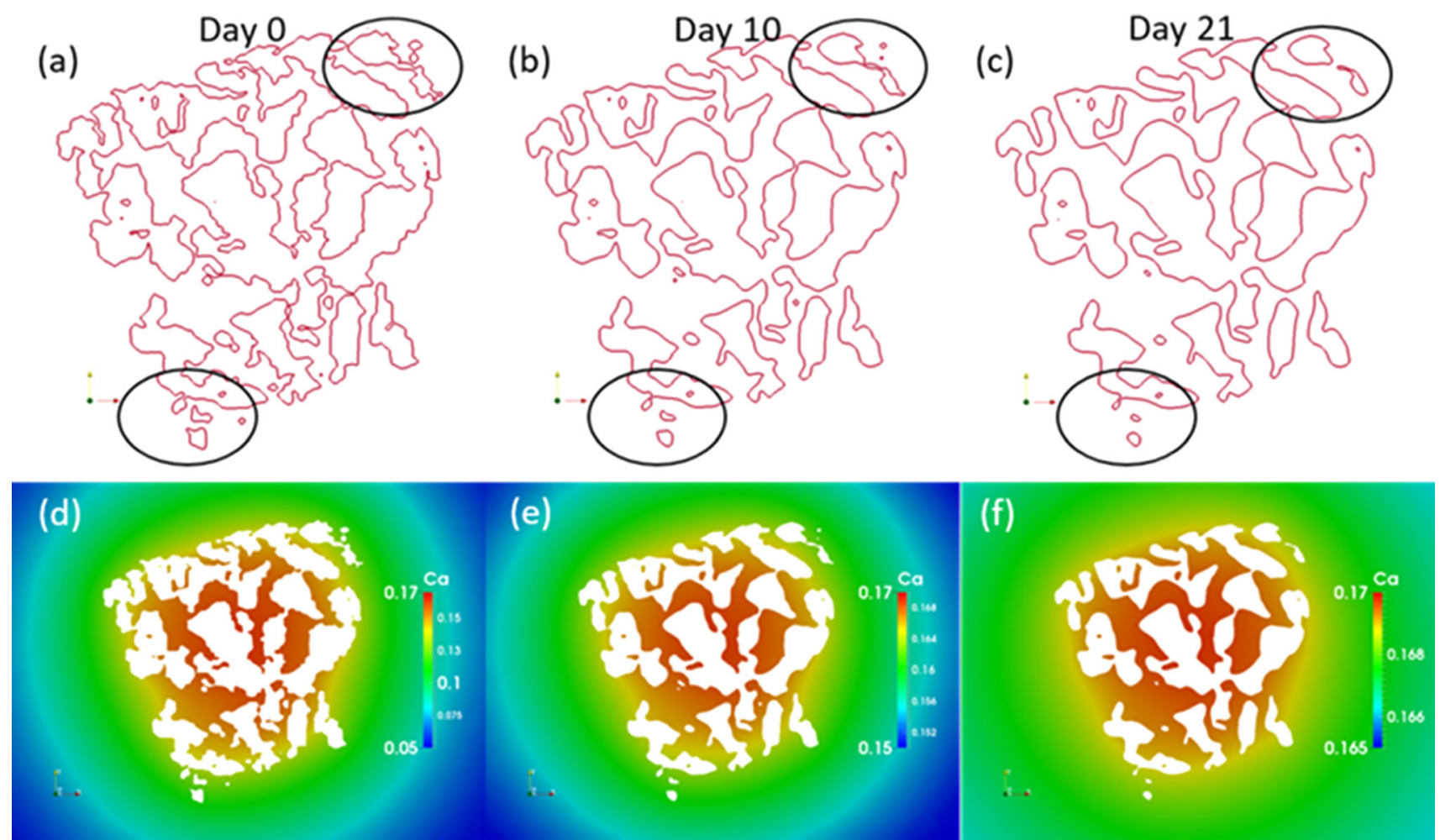

Fig. 5 Dissolution behaviour of Bio-Oss ${ }^{\circledR}$ predicted mathematically. a Scaffold shape at day 0, b at day 10, and $\mathbf{c}$ at day 21 . d-f Local Ca ${ }^{2+}$ ion concentration during dissolution at day 0,10 and 21. The circles in images a-c highlight degradation of the scaffold

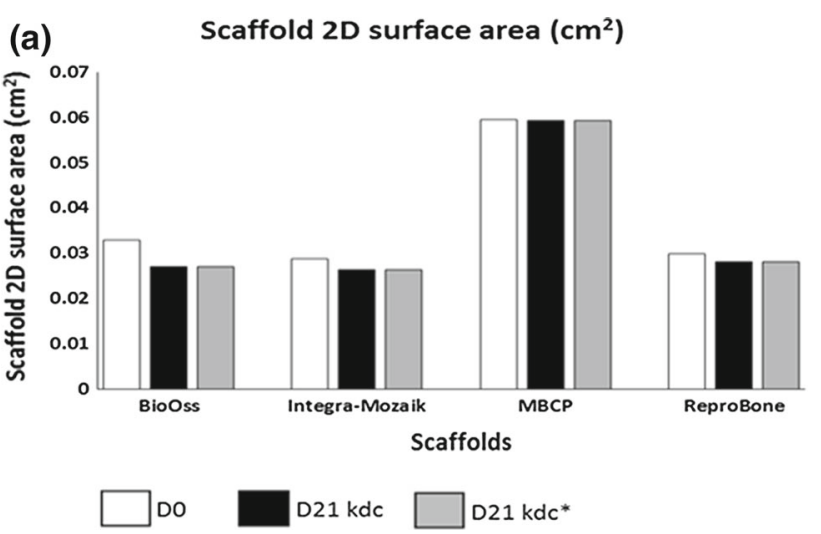

Fig. 6 a Change in the scaffold surface area (2D) as predicted by the model using $k_{\mathrm{dc}}$ and $k_{\mathrm{dc}}^{*}$. D0, day 0; D21, day 21. b Quantitative results of the scaffold $\mathrm{CaP}$ volume fraction (\%). In $\mathbf{b}$, the data have been nor-

\section{Discussion}

In this study, a combined experimental-modelling approach was used to describe the in vitro dissolution of CaP-based scaffolds over time. First, the in vitro dissolution kinetics of chemically and structurally different $\mathrm{CaP}$ biomaterials were investigated in PBS. Proceeding from the in vitro experiments, a 2D FEM model based on the diffusion-dissolution equation along with the level-set equation was developed to predict the in vitro dissolution behaviour of CaP-based (b) CaP volume fraction (\%)

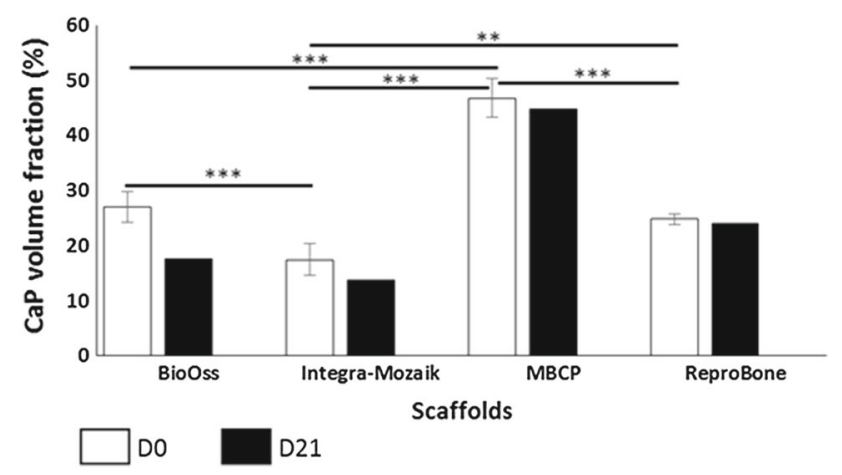

malized to the initial total scaffold volume (TSV) leading to fractions. Statistical significance: $* * p<0.01$; *** $p<0.001$ ( $n=5$ for day 0 and $n=1$ for day 21). D0, day 0; D21, day 21

scaffolds in PBS solution. The model parameters were either determined from the experimental results or derived from the results described in the literature or estimated. The model was able to capture the in vitro dissolution of $\mathrm{Ca}^{2+}$ ions in accordance with the experimental reports. Additionally, a single-parameter sensitivity analysis was carried out to determine the influence of specific model parameters on the predicted outcome. This obtained model is able to predict the dissolution behaviour of CaP-based scaffolds as well as the local calcium concentration inside the scaffold based on 

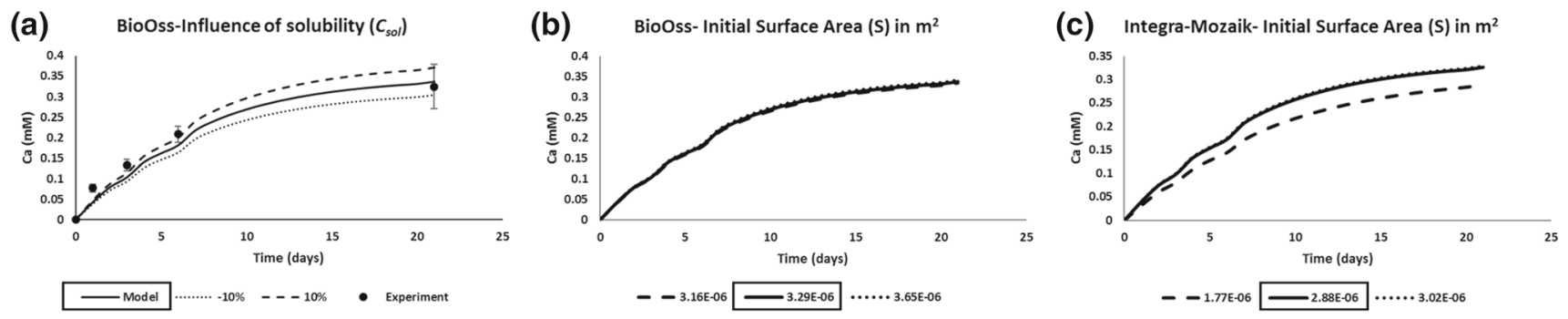

Fig. 7 Parameter sensitivity analyses $-\mathbf{a}$ influence of the solubility $\left(C_{\text {sol }}\right)$ on the $\mathrm{Ca}^{2+}$ ions release for Bio-Oss ${ }^{\circledR}$. In a, scatter plot represents the experimental results. Influence of using different images with varying initial $\mathrm{CaP}$ surface area $(S)$ on the modelling outcome b Bio-

Oss ${ }^{\circledR}$ and $\mathbf{c}$ Integra-Mozaik ${ }^{\mathrm{TM}}$. Boxed values indicate the values used in the analyses. In $\mathbf{b}$ and $\mathbf{c}$ the lines that are not visible coincide with the solid line (a)

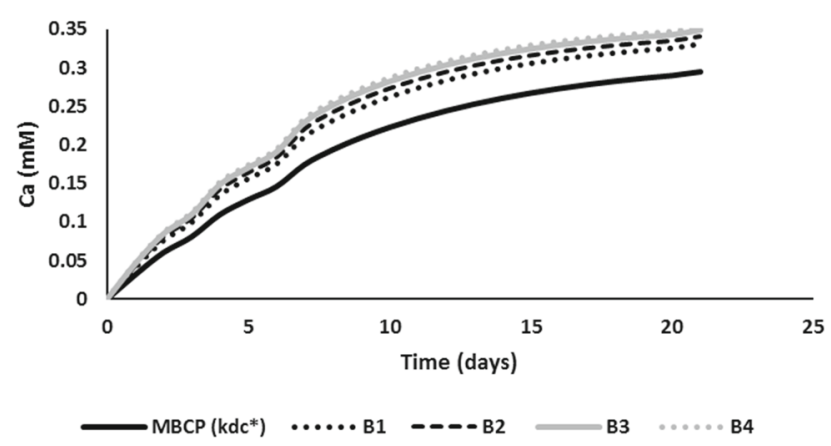

(b)

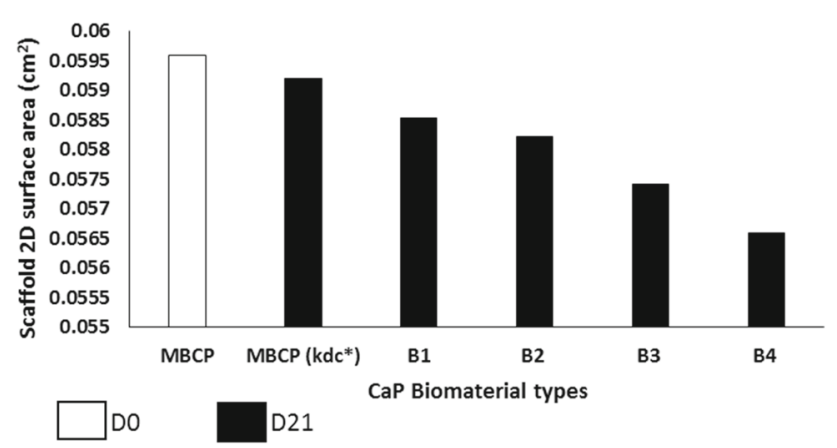

MBCP (kdc*)- $60 \% \mathrm{HA}+40 \% \beta-\mathrm{TCP}$

B1- $50 \% \mathrm{HA}+50 \% \beta-\mathrm{TCP}$

B2- $40 \%$ HA $+60 \% \beta-T C P$

B3- $20 \% \mathrm{HA}+80 \% \beta-\mathrm{TCP}$

B4- $100 \% \beta-T C P$

Fig. 8 Investigating the dissolution and degradation behaviour of a biomaterial with multiple combinations of $\beta$-TCP and HA. a Dissolution and b degradation behaviour for scaffolds with a geometry as that of MBCP but a composition that is a mix of $\beta$-TCP and HA

the parameters that can be obtained from microCT imaging. In order to limit the amount of experimental work needed to make predictions for scaffold materials within the training set, relations were derived between the scaffold compositional characteristics and the $k_{\mathrm{dc}}$ and $k_{\mathrm{sc}}$ values and then tested on the training set itself. Finally, using the PLSRderived linear relationships, the model was used to investigate the dissolution behaviour of a biomaterial with different combinations of HA and $\beta$-TCP.

In this study, the in vitro dissolution kinetics of biomaterials broadly classified as fast degrading (Bio-Oss ${ }^{\circledR}$ and Integra-Mozaik ${ }^{\mathrm{TM}}$ ) and slow degrading $\left(\mathrm{MBCP}^{\mathrm{TM}}\right.$ and ReproBone $^{\mathrm{TM}}$ ) scaffolds were investigated in PBS. The four biomaterials contained different chemical formation and volume percentages of $\mathrm{CaP}$, along with different structural characteristics such as collagen volume, total scaffold volume (TSV) and total material volume (TMV). The observed chemical and structural variations between scaffold types allowed for differences in release kinetics of $\mathrm{Ca}^{2+}$ ions in
PBS medium, where the fast degrading scaffolds were found to have higher in vitro dissolution than the slow degrading scaffolds (Fig. 4). It is worth mentioning that the dissolution of bovine bone granules in Bio-Oss ${ }^{\circledR}$ is higher when compared to synthetic HA (Mezahi et al. 2009). We did not detect precipitate formation.

The reported mathematical analysis of in vitro dissolution behaviour of $\mathrm{CaP}$-based biomaterials is the most mechanistic model published to date. Previous models describing CaPbased scaffold dissolution behaviour were either theoretical in nature (Bohner and Baumgart 2004) or lattice-based that did not capture the actual geometry of the CaP scaffolds. Additionally, the lattice based models used a phenomenological description of the degradation process (Adachi et al. 2006; Byrne et al. 2007; Sun et al. 2013). However, by explicitly incorporating dedicated experimental results along with taking into account the accurate geometrical shape of the scaffolds, this study takes an important step towards the use of in silico modelling in biomaterial design. This study focuses 
on measurements and modelling of $\mathrm{Ca}^{2+}$ ions dissolution, so it did not consider the influence of the microporosity, collagen distribution, $\mathrm{CaP}$ crystallinity or crystal size, precipitation, phosphate $\left(\mathrm{PO}_{4}^{3-}\right)$ ions dissolution or changing collagen volume on the diffusivity behaviour of $\mathrm{Ca}^{2+}$ ions. Ultimately, these influences need to be included comprehensively in the model (Gao and Fagerness 1995). Additional simplifications made in the course of this study pertain mainly to the modelling aspects. The first simplification to be dealt within the future is the fact that the model only looks at dissolution kinetics in 2D, thereby neglecting any 3D spatial aspects, which might influence the overall numerical solution. It has been reported that the parameter values estimated by the $2 \mathrm{D}$ model could be overestimated with respect to the ones predicted by the 3D model, which could influence the overall output of the model (Nava et al. 2013). The second simplification included in the model was exclusion of solving the fluid flow due to rotation during the dissolution experiment as well as the advection of $\mathrm{Ca}^{2+}$ ions due to fluid flow and the movement of scaffold due to rotation. This was done to keep the model computationally inexpensive and is in line with other models studying drug release from carriers under dynamic conditions (Arifin et al. 2006; Frenning et al. 2003; Snorradóttir et al. 2013). It is worth stating that this model can be adapted to potentially recapitulate the local in vivo (where the fluid flow is not so important) $\mathrm{Ca}^{2+}$ ion concentrations during the dissolution process by making adjustments to the existing parameters and including additional parameters specific to the in vivo environment.

The values for unknown parameters such as dissolution constant $\left(k_{\mathrm{dc}}\right)$ and degradation constant $\left(k_{\mathrm{sc}}\right)$ for each scaffold type were determined by calibrating the model to the experimental release data of $\mathrm{Ca}^{2+}$ ions. It is evident from Fig. 4 that there was overall an acceptable though not perfect agreement between the predicted (solid lines) and the experimentally measured (scatter plots) release profiles. It is also evident from Fig. 4 that the model is not able to accurately capture the initial release. This could be due to the fact that the model does not consider advection of $\mathrm{Ca}^{2+}$ ions due to fluid flow. Moreover, we did observe that using a higher $k_{\mathrm{dc}}$ value captured the initial release but greatly overestimated the release at day 21 . Therefore, the value of $k_{\mathrm{dc}}$ was estimated by keeping the best possible balance between underestimation of initial and overestimation of final calcium release profile. Due to a substantial lack of relevant data on this matter, we restricted ourselves to the use of a fixed value for kdc in this study. However, using the value of $k_{d c}$ as an exponentially decreasing function rather than a constant value would give a better fit with experimental data. The use of $k_{d c}$ as an exponentially decreasing function could take into account the effect of adhesion of precipitated ions to the surface as well as the effect of changing $\mathrm{pH}$ during the dissolution process.
Additionally, the model was able to predict the spatialtemporal degradation and dissolution of the scaffolds (Fig. 5a-f). This spatial information represents one of the clear added values of computational modelling in the context of designing new biomaterials. No measurement devices exist to date that allow this spatial representation of the local calcium concentration-even though these local concentrations are what is felt by the cells seeded onto the scaffold. Computational models therefore allow to link the insight from in vitro experiments by studying the effect of $\mathrm{Ca}^{2+}$ ions on cellular behaviour (Arifin et al. 2006) to the design of optimized biomaterials. Furthermore, the model predicted higher degradation of $\mathrm{CaP}$ for Bio-Oss ${ }^{\circledR}$ and Integra-Mozaik ${ }^{\mathrm{TM}}$, which was expected due to their higher dissolution behaviour (Fig. 6). Moreover, the single-parameter sensitivity analyses such as the one carried out in this study was able to identify the influence of a few estimated model parameters on the final outcome. We found that the solubility $\left(C_{\text {sol }}\right)$ had a quantitative influence on the simulation results (Fig. 7a). In addition, we observed that the model results were not influenced by the choice in representative 2D image for the investigated scaffolds, except for Integra-Mozaik ${ }^{\mathrm{TM}}$ (Fig. 7b, c). This was mainly due to heterogeneous structure of Integra-Mozaik ${ }^{\mathrm{TM}}$ which resulted in variability of surface area $(S)$ of $\mathrm{CaP}$ across different image slices. Subsequently, the estimated values for $k_{\mathrm{dc}}$ and $k_{\mathrm{sc}}$ were connected to the material composition properties (such as $\%$ bovine bone granules, $\% \beta$-TCP and $\% \mathrm{HA}$ ) of the scaffolds through PLSR to derive $k_{\mathrm{dc}}^{*}$ and $k_{\mathrm{sc}}^{*}$ values. This type of relationships allows estimating dissolution properties of scaffolds based on material characteristics without performing in vitro tests. The current relationships, being linear in nature and derived from a small sample size, are only indicative and have to be re-evaluated when additional data becomes available (additional CaP-based scaffold types and $n>3$ for heterogeneous scaffolds). Yet, the approach taken is simple and easily allows for continuous improvement. In addition to allowing to estimating the in vitro behaviour of $\mathrm{CaP}$ containing scaffolds, the current model can also be used in a more proactive way, namely in the design of new $\mathrm{CaP}$ containing biomaterials. If a specific calcium release window is desired (in order to obtain a specific biological function), the model can be used to find the specific geometrical and compositional properties of the scaffold(s) that would lead to the desired degradation behaviour. Yet, a limitation of the currently used simple equation for $k_{\mathrm{sc}}^{*}$ is it's incapacity to predict a relevant $k_{\mathrm{sc}}^{*}$ value for materials containing more than $60 \%$ HA. Finally, Fig. 8 shows that a higher amount of $\beta$-TCP in the biomaterial resulted in higher dissolution and degradation whereas the effect of HA on biomaterial dissolution and degradation was completely the opposite, which is in line with common knowledge on CaP-based biomaterials (Hong et al. 2014). 


\section{Conclusion}

This study illustrates the integrative experimental-modelling approach to elucidate mathematically the local in vitro dissolution kinetics of CaP-based scaffolds. The model is capable of predicting experimentally unmeasurable local in vitro $\mathrm{Ca}^{2+}$ ion concentrations that affect the bone cell chemotaxis and proliferation. Even though we designed and conducted dedicated experiments to determine specific model parameter values, the mathematical model still contains some estimated parameter values due to the absence of accurate, quantitative data in literature and the complexity of making quantitative in vitro measurements. But despite the simplifications and estimations, the model is able to recapitulate experimental findings qualitatively. The mathematical modelling of dissolution of CaP-based biomaterials has significant potential to facilitate understanding and development of complex bone tissue engineering constructs (i.e. scaffolds with cells and/or growth factors) in the future. It can be used to study numerous design parameters and avoid excessive experimentation, thus saving time and resources.

Acknowledgments Céline Smekens is gratefully acknowledged for her work as a master student on measuring the $\mathrm{Ca}^{2+}$ ions release using micro ion electrode. Bachelor students Antoine Delacroix and Simon Bruneau (ESEO, Angers, France) are gratefully acknowledged for their work on development of Morphing CiTy (ULg, Liege, Belgium). Varun Manhas and Yann Guyot are funded by Belgian National Fund for Scientific Research (FNRS) Grant FRFC 2.4564.12. Greet Kerckhofs and Yoke Chin Chai are financed by the postdoctoral Grant of the Research Foundation-Flanders (FWO/12R4315N and 1.5.172.13N-Interdisc.http://www.fwo.be/en/). The research leading to these results has received funding from the European Research Council under the European Union's Seventh Framework Programme (FP/2007-2013)/ERC Grant Agreement No. 279100. The microCT images have been generated on the X-ray computed tomography facilities of the Department of Materials Engineering of the KU Leuven, financed by the Hercules Foundation (Project AKUL 09/001: Micro- and nanoCT for the hierarchical analysis of materials). This work is part of Prometheus, the KU Leuven R\&D Division of Skeletal Tissue Engineering (http://www. kuleuven.be/prometheus).

\section{Compliance with ethical standards}

Conflict of interest The authors declare that they have no conflict of interest.

\section{References}

Adachi T, Osako Y, Tanaka M, Hojo M, Hollister SJ (2006) Framework for optimal design of porous scaffold microstructure by computational simulation of bone regeneration. Biomaterials 27:39643972

Arifin DY, Lee LY, Wang C-H (2006) Mathematical modeling and simulation of drug release from microspheres: implications to drug delivery systems. Adv Drug Deliv Rev 58:1274-1325

Bianchi M et al (2014) Substrate geometry directs the in vitro mineralization of calcium phosphate ceramics. Acta Biomater 10:661-669
Bléry P et al (2014) Evaluation of new bone formation in irradiated areas using association of mesenchymal stem cells and total fresh bone marrow mixed with calcium phosphate scaffold. J Mater Sci Mater Med 25:2711-2720

Bohner M, Baumgart F (2004) Theoretical model to determine the effects of geometrical factors on the resorption of calcium phosphate bone substitutes. Biomaterials 25:3569-3582

Brazel CS, Peppas NA (2000) Modeling of drug release from swellable polymers. Eur J Pharm Biopharm 49:47-58

Byrne DP, Lacroix D, Planell JA, Kelly DJ, Prendergast PJ (2007) Simulation of tissue differentiation in a scaffold as a function of porosity. Young's modulus and dissolution rate: application of mechanobiological models in tissue engineering. Biomaterials 28:5544-5554

Carlier A, Chai YC, Moesen M, Theys T, Schrooten J, Van Oosterwyck H, Geris L (2011) Designing optimal calcium phosphate scaffoldcell combinations using an integrative model-based approach. Acta Biomater 7:3573-3585

Chai YC et al (2012a) Current views on calcium phosphate osteogenicity and the translation into effective bone regeneration strategies. Acta Biomater 8:3876-3887

Chai YC et al (2012b) Ectopic bone formation by 3D porous calcium phosphate-Ti6Al4V hybrids produced by perfusion electrodeposition. Biomaterials 33:4044-4058

Chai YC et al (2012c) Mechanisms of ectopic bone formation by human osteoprogenitor cells on CaP biomaterial carriers. Biomaterials 33:3127-3142

Charles-Harris M, Koch MA, Navarro M, Lacroix D, Engel E, Planell JA (2008) A PLA/calcium phosphate degradable composite material for bone tissue engineering: an in vitro study. J Mater Sci Mater Med 19:1503-1513

Danoux CB et al (2015) Elucidating the individual effects of calcium and phosphate ions on hMSCs by using composite materials. Acta Biomater 17:1-15

Dash S, Murthy PN, Nath L, Chowdhury P (2010) Kinetic modeling on drug release from controlled drug delivery systems. Acta Pol Pharm 67:217-223

Fredenberg S, Wahlgren M, Reslow M, Axelsson A (2011) The mechanisms of drug release in poly (lactic-co-glycolic acid)-based drug delivery systems - a review. Int J Pharm 415:34-52

Frenning G (2003) Theoretical investigation of drug release from planar matrix systems: effects of a finite dissolution rate. J Control Release 92:331-339

Frenning G (2004) Theoretical analysis of the release of slowly dissolving drugs from spherical matrix systems. J Control Release 95:109-117

Frenning G, Strømme M (2003) Drug release modeled by dissolution, diffusion, and immobilization. Int J Pharm 250:137-145

Frenning G, Tunón Å, Alderborn G (2003) Modelling of drug release from coated granular pellets. J Control Release 92:113-123

Frenning G, Brohede U, Strømme M (2005) Finite element analysis of the release of slowly dissolving drugs from cylindrical matrix systems. J Control Release 107:320-329

Gao P, Fagerness PE (1995) Diffusion in HPMC gels. I. Determination of drug and water diffusivity by pulsed-field-gradient spin-echo NMR. Pharm Res 12:955-964

Guyot Y, Papantoniou I, Chai YC, Van Bael S, Schrooten J, Geris L (2014) A computational model for cell/ECM growth on 3D surfaces using the level set method: a bone tissue engineering case study. Biomech Model Mechanobiol 13:1361-1371

Hecht F (2012) New development in freefem++. J Numer Math 20:251266

Hong M-H, Kim S-M, Om J-Y, Kwon N, Lee Y-K (2014) Seeding cells on calcium phosphate scaffolds using hydrogel enhanced osteoblast proliferation and differentiation. Ann Biomed Eng 42:1424-1435 
Horbett T, Waldburger J, Ratner B, Hoffman A (1988) Cell adhesion to a series of hydrophili-hydrophobic copolymers studies with a spinning disc apparatus. J Biomed Mater Res 22:383-404

Karadzic I, Vucic V, Jokanovic V, Debeljak-Martacic J, Markovic D, Petrovic S, Glibetic M (2015) Effects of novel hydroxyapatitebased 3D biomaterials on proliferation and osteoblastic differentiation of mesenchymal stem cells. J Biomed Mater Res Part A 103:350-357

Kaunisto E, Tajarobi F, Abrahmsen-Alami S, Larsson A, Nilsson B, Axelsson A (2013) Mechanistic modelling of drug release from a polymer matrix using magnetic resonance microimaging. Eur $\mathrm{J}$ Pharm Sci 48:698-708

Lanao RPF, Leeuwenburgh SC, Wolke JG, Jansen JA (2011) Bone response to fast-degrading, injectable calcium phosphate cements containing PLGA microparticles. Biomaterials 32:8839-8847

Lao LL, Peppas NA, Boey FYC, Venkatraman SS (2011) Modeling of drug release from bulk-degrading polymers. Int J Pharm 418:2841

Lobo SE, Glickman R, da Silva WN, Arinzeh TL, Kerkis I (2015) Response of stem cells from different origins to biphasic calcium phosphate bioceramics. Cell Tissue Res 361: 477-495

Masaro L, Zhu X (1999) Physical models of diffusion for polymer solutions, gels and solids. Prog Polym Sci 24:731-775

Mazón P, García-Bernal D, Meseguer-Olmo L, Cragnolini F, Piedad N (2015) Human mesenchymal stem cell viability, proliferation and differentiation potential in response to ceramic chemistry and surface roughness. Ceram Int 41:6631-6644

Mezahi F, Oudadesse H, Harabi A, Lucas-Girot A, Le Gal Y, Chaair H, Cathelineau G (2009) Dissolution kinetic and structural behaviour of natural hydroxyapatite vs. thermal treatment. J Therm Anal Calorim 95:21-29

Nava MM, Raimondi MT, Pietrabissa R (2013) A multiphysics 3D model of tissue growth under interstitial perfusion in a tissueengineering bioreactor. Biomech Model Mechanobiol 12:11691179

Polakovič M, Görner T, Gref R, Dellacherie E (1999) Lidocaine loaded biodegradable nanospheres: II. Modelling of drug release. J Control Release 60:169-177

Ribeiro AC, Barros MC, Teles AS, Valente AJ, Lobo VM, Sobral AJ, Esteso M (2008) Diffusion coefficients and electrical conductivities for calcium chloride aqueous solutions at $298.15 \mathrm{~K}$ and 310.15 K. Electrochimica Acta 54:192-196
Roberts SJ, Geris L, Kerckhofs G, Desmet E, Schrooten J, Luyten FP (2011) The combined bone forming capacity of human periosteal derived cells and calcium phosphates. Biomaterials 32:4393-4405

Shannon RT (1976) Revised effective ionic radii and systematic studies of interatomic distances in halides and chalcogenides. Acta Crystallogr Sect A Cryst Phys Diffr Theor Gen Crystallogr 32:751-767

Shih Y-RV et al (2014) Calcium phosphate-bearing matrices induce osteogenic differentiation of stem cells through adenosine signaling. Proc Natl Acad Sci 111:990-995

Siepmann J, Göpferich A (2001) Mathematical modeling of bioerodible, polymeric drug delivery systems. Adv Drug Deliv Rev 48:229-247

Siepmann J, Siepmann F (2008) Mathematical modeling of drug delivery. Int J Pharm 364:328-343

Siepmann J, Peppas NA (2011) Higuchi equation: derivation, applications, use and misuse. Int J Pharm 418:6-12

Siepmann J, Siepmann F (2013) Mathematical modeling of drug dissolution. Int J Pharm 453:12-24

Siepmann J, Kranz H, Bodmeier R, Peppas N (1999) HPMC-matrices for controlled drug delivery: a new model combining diffusion, swelling, and dissolution mechanisms and predicting the release kinetics. Pharm Res 16:1748-1756

Snorradóttir BS, Jónsdóttir F, Sigurdsson ST, Thorsteinsson F, Másson M (2013) Numerical modelling and experimental investigation of drug release from layered silicone matrix systems. Eur J Pharm Sci 49:671-678

Sonnaert M, Luyten FP, Schrooten J, Papantoniou I (2015) Bioreactorbased online recovery of human progenitor cells with uncompromised regenerative potential: a bone tissue engineering perspective. PloS ONE 10:e0136875

Sun X, Kang Y, Bao J, Zhang Y, Yang Y, Zhou X (2013) Modeling vascularized bone regeneration within a porous biodegradable $\mathrm{CaP}$ scaffold loaded with growth factors. Biomaterials 34:4971-4981

Wu L, Ding J (2005) Effects of porosity and pore size on in vitro degradation of three-dimensional porous poly (D, L-lactide-coglycolide) scaffolds for tissue engineering. J Biomed Mater Res Part A 75:767-777

Young M, Carroad P, Bell R (1980) Estimation of diffusion coefficients of proteins. Biotechnol Bioeng 22:047-955 